\title{
Genome-guided insight into the methylotrophy of Paracoccus aminophilus JCM 7686
}

\author{
Lukasz Dziewit ${ }^{1 * \dagger}$, Jakub Czarnecki ${ }^{1 \dagger}$, Emilia Prochwicz ${ }^{1}$, Daniel Wibberg ${ }^{2}$, \\ Andreas Schlüter ${ }^{2}$, Alfred Pühler ${ }^{2}$ and Dariusz Bartosik ${ }^{1}$ \\ ${ }^{1}$ Department of Bacterial Genetics, Institute of Microbiology, Faculty of Biology, University of Warsaw, Warsaw, Poland, \\ ${ }^{2}$ Institute for Genome Research and Systems Biology, Center for Biotechnology (CeBiTec), Bielefeld University, Bielefeld, \\ Germany
}

Paracoccus aminophilus JCM 7686 (Alphaproteobacteria) is a facultative, heterotrophic methylotroph capable of utilizing a wide range of $\mathrm{C} 1$ compounds as sole carbon and energy sources. Analysis of the JCM 7686 genome revealed the presence of genes involved in the oxidation of methanol, methylamine, dimethylamine, trimethylamine, $\mathrm{N}, \mathrm{N}$-dimethylformamide, and formamide, as well as the serine cycle, which appears to be the only $\mathrm{C} 1$ assimilatory pathway in this strain. Many of these genes are located in different extrachromosomal replicons and are not present in the genomes of most members of the genus Paracoccus, which strongly suggests that they have been horizontally acquired. When compared with Paracoccus denitrificans Pd1222 (type strain of the genus Paracoccus), P. aminophilus JCM 7686 has many additional methylotrophic capabilities (oxidation of dimethylamine, trimethylamine, $N, N$-dimethylformamide, the serine cycle), which are determined by the presence of three separate gene clusters. Interestingly, related clusters form compact methylotrophy islands within the genomes of Paracoccus sp. N5 and many marine bacteria of the Roseobacter clade.

\footnotetext{
Keywords: Paracoccus aminophilus JCM 7686, methylotrophy, serine cycle, methanol, methylated amine, $N, N$ dimethylformamide, chromid, plasmid
}

\section{Introduction}

The genus Paracoccus (Alphaproteobacteria) comprises bacteria isolated from various pristine and polluted environments (e.g., soil, marine sediments, seawater, biofilters, activated sludge, or human tissues) (Urakami et al., 1990; Siller et al., 1996; Lipski et al., 1998; Tsubokura et al., 1999; Funke et al., 2004; Lee et al., 2004; Liu et al., 2006). These bacteria show diverse metabolic properties and can switch between different growth modes-for example, heterotrophic growth on a wide range of organic compounds vs. chemolithoautotrophic growth on reduced sulfur compounds, hydrogen or ferrous ions as the energy sources, or aerobic respiration vs. anaerobic nitrate respiration (Kelly et al., 2006). Because of their degradative capabilities, many Paracoccus spp. strains are suitable for application in bioremediation systems. They have been successfully employed in the bioremediation of soils contaminated with polycyclic aromatic hydrocarbons (PAHs, Sun et al., 2013) and in the removal of nitrate and $N, N$-dimethylformamide (DMF) from wastewater (Liu et al., 2012; Sanjeevkumar et al., 2013). Moreover, their ability to utilize pesticides and insecticides, including the highly toxic chlorpyrifos, 3,5,6-trichloro-2-pyridinol, methyl parathion, and carbonfuran, has also been demonstrated (Li et al., 2011). 
About 50\% of known Paracoccus spp. strains are described as methylotrophs, i.e., organisms utilizing C1 compounds (reduced carbon compounds containing no carbon-carbon bonds) as sole carbon and energy sources (Baker et al., 1998). Methylotrophs play an important role in global carbon, nitrogen, and sulfur cycling, and for this reason their biochemistry has been subjected to extensive studies (Trotsenko and Murrell, 2008; Chistoserdova, 2011). As described by Chistoserdova (2011), the methylotrophy process can be divided into three stages: (i) primary oxidation of $\mathrm{C} 1$ substrates, which results in formaldehyde, methyl- or methylene-tetrahydrofolate $\left(\mathrm{CH}_{3}-\right.$ THF or $\mathrm{CH}_{2}=\mathrm{THF}$ ) formation, (ii) oxidation of formaldehyde, $\mathrm{CH}_{3}$-THF or $\mathrm{CH}_{2}=\mathrm{THF}$ to $\mathrm{CO}_{2}$, and (iii) assimilation of $\mathrm{C} 1$ units. The final stage may be performed via the ribulose monophosphate (RuMP) cycle, the serine cycle or the CalvinBenson-Bassham (CBB) cycle (Chistoserdova, 2011).

Paracoccus denitrificans Pd1222 (type strain of the genus Paracoccus, Kelly et al., 2006) exemplifies so-called autotrophic methylotrophs (Chistoserdova, 2011), assimilating $\mathrm{CO}_{2}$ derived from the oxidation of $\mathrm{C} 1$ compounds [in Pd1222 these are methanol $(\mathrm{MeOH})$ or methylamine (MA)] via the Calvin cycle (Baker et al., 1998). Other methylotrophic strains of Paracoccus spp. have been poorly characterized. Interestingly, in comparison with $P$. denitrificans, these strains show significant differences in their methylotrophic metabolism, not only in the range of $\mathrm{C} 1$ compounds utilized [many strains are able to oxidize trimethylamine (TMA), trimethylamine $\mathrm{N}$-oxide (TMAO), dimethylamine (DMA), dichloromethane or DMF] (Urakami et al., 1990; Kim et al., 2001, 2003; Turova et al., 2001), but also in the central metabolic pathways mediating $\mathrm{C} 1$ unit assimilation (Beck et al., 2015).

Very recently, a set of genes encoding the enzymes of the serine cycle have been identified in Paracoccus sp. N5 (Beck et al., 2015). Since this strain also encodes all enzymes of the Calvin cycle it was classified as a facultatively autotrophic methylotroph (Beck et al., 2015). In this work we have characterized Paracoccus aminophilus JCM 7686, which represents another metabolic group of methylotrophic bacteria-the heterotrophic serine cycle methylotrophs. This strain does not encode ribulose-1,5bisphosphate carboxylase/oxygenase (RuBisCO), crucial for the Calvin cycle, so its methylotrophic properties exclusively rely on the serine cycle.

The multipartite genome of $P$. aminophilus JCM 7686 was described in detail in our previous report (Dziewit et al., 2014). It is composed of a single circular chromosome (3.6 Mb) and eight circular extrachromosomal replicons. The functional analyses of those replicons revealed that six of them (pAMI1, pAMI2, pAMI3, pAMI4, pAMI7, and pAMI8) are plasmids and two (pAMI5 and pAMI6) are chromids (i.e., elements essential for host viability and sharing characteristics of both chromosomes and plasmids) (Dziewit et al., 2007, 2011a,b, 2014). In the present study, bioinformatic sequence analyses of the JCM 7686 genome together with functional characterization of selected genes have provided deeper insight into both the biochemistry of the methylotrophy of this strain and the role of the extrachromosomal genetic elements in determination of its methylotrophic capability.

\section{Materials and Methods}

\section{Strains, Plasmids, and Culture Conditions}

The strains used in this study are described in Table S1. All strains were grown in lysogeny broth (LB) (Sambrook and Russell, 2001) at $37^{\circ} \mathrm{C}$ [E. coli TG1 (Gibson, 1984) and S171 (Simon et al., 1983)] and $30^{\circ} \mathrm{C}$ [P. aminophilus JCM 7686R (Bartosik et al., 2002)]. P. aminophilus was also grown in minimal salts medium (AC) (Wood and Kelly, 1977) at $30^{\circ} \mathrm{C}$. When necessary, the media were supplemented with kanamycin $(50 \mu \mathrm{g} / \mathrm{ml})$, tetracycline $(2 \mu \mathrm{g} / \mathrm{ml}$ for Paracoccus spp. or $20 \mu \mathrm{g} / \mathrm{ml}$ for E. coli), chloramphenicol $(12.5 \mu \mathrm{g} / \mathrm{ml})$, rifampicin $(50 \mu \mathrm{g} / \mathrm{ml})$, gentamicin $(10 \mu \mathrm{g} / \mathrm{ml})$, or sucrose $(11 \% \mathrm{w} / \mathrm{v})$. The following compounds were used as the carbon source in minimal media: L-arabinose $(0.2 \% \mathrm{w} / \mathrm{v}), \quad N, N$-dimethylformamide $(20 \mathrm{mM})$, trimethylamine $(20 \mathrm{mM})$, dimethylamine $(10 \mathrm{mM})$, methylamine (10 $\mathrm{mM})$, formamide $(20 \mathrm{mM})$, and methanol $(20 \mathrm{mM})$. All plasmids used [i.e., pBBR1MCS-3 (Kovach et al., 1994), pBBR1MCS-5 (Kovach et al., 1994), pDIY-KM (Dziewit et al., 2011a), pDS132 (Philippe et al., 2004), pKRP12 (Reece and Phillips, 1995), pRK2013 (Ditta et al., 1980)] and constructed in this study are described in Table $\mathbf{S 2}$.

\section{Standard Genetic Manipulations}

The isolation of DNA and common DNA manipulation methods were performed as described by Sambrook and Russell (2001). PCR was performed in an Eppendorf Mastercycler with pDIYKM, pKRP12 or total DNA of P. aminophilus as the template, appropriate oligonucleotide primers (Table S3), dNTP mixture and Phusion High-Fidelity DNA polymerase (Thermo Scientific; with supplied HF buffer). Transformation of E. coli strains was performed according to the method of Kushner (1978). Bi- and tri-parental matings were performed as previously described (Bartosik et al., 2001). For triparental mating, overnight cultures of the donor strain E. coli TG1, the appropriate recipient strain, and E. coli $\mathrm{DH} 5 \alpha$ carrying the helper plasmid pRK2013 were mixed in a ratio 1:2:1. For biparental mating, overnight cultures of the donor strain E. coli S17-1 carrying a mobilizable vector and the appropriate recipient strain were mixed in a ratio $1: 1$. Then $100 \mu \mathrm{l}$ of the mixture was spread on a plate with solidified LB medium and incubated overnight at $30^{\circ} \mathrm{C}$. Then the bacteria were washed off the plate, and the suitable dilutions were plated on appropriate selective media to select transconjugants (Bartosik et al., 2001).

\section{Gene Disruption}

Deletion of selected P. aminophilus JCM 7686 genes was performed using a gene replacement method. DNA cassettes for gene disruption, containing an antibiotic resistance gene flanked by PCR-amplified DNA fragments (ca. $500 \mathrm{bp}$ ) homologous to the DNA regions surrounding the gene targeted for disruption, were created by overlap extension PCR with specific primers (Table S3) or by restriction cloning (Table S2). The obtained DNA cassettes were transferred by biparental mating from $E$. coli S17-1 into rifampicin resistant $P$. aminophilus JCM 7686R cells on $s a c B$ gene-containing vector $\mathrm{pDS} 132$, unable to replicate in Alphaproteobacteria. Double-cross recombinants were selected 
on appropriate medium containing rifampicin, sucrose and kanamycin or tetracycline, depending on the antibiotic resistance gene used for cassette construction. The correctness of the generated disruptions was verified by sequencing DNA fragments amplified by PCR using appropriate primer pairs (Table S3).

\section{RT-qPCR}

Total RNAs used for the RT-qPCR analyses were isolated from $P$. aminophilus cells grown on TMA or arabinose as the sole carbon and energy source. The strain was cultured in appropriate minimal media in three biological repeats and cells were collected during late exponential phase. RNA was isolated using TRI Reagent ${ }^{\circledR}$ Solution (Ambion) according to the manufacturer's recommendations. Contaminating DNA was removed using DNA-free ${ }^{\mathrm{TM}}$, DNase Treatment \& Removal (Ambion) according to the manufacturer's recommendations. The total RNA was transcribed into cDNA using the Maxima First Strand cDNA Synthesis Kit for RT-qPCR (Thermo Scientific) according to the manufacturer's instruction. RT-qPCR reactions were carried out in LightCycler ${ }^{\circledR} 480$ Instrument II (Roche) using $5 \times$ HOT FIREPol $^{\circledR}$ EvaGreen ${ }^{\circledR}$ qPCR Mix Plus (no ROX). Oligonucleotide primers used in the study are listed in Table S3. Relative quantification of gene transcription was performed using the comparative $C_{t}$ (threshold cycle) method.

\section{Bioinformatics}

The putative function of particular genes was assigned using BLAST programs (Altschul et al., 1997) and PRIAM tool (Claudel-Renard et al., 2003) as previously described (Heinl et al., 2012). Metabolic pathways were recognized and described using Pathway tools (Karp et al., 2010), the MetaCyc database (Caspi et al., 2008) and GenDB 2.0 (Meyer et al., 2003). For the identification of methylotrophy-linked genes/proteins a BLASTn/BLASTp analysis comparing the sequence of each gene/protein with the genome/proteome of a particular Paracoccus strain was performed. Strict cutoff values were applied for this analysis: $e<10^{-40}, 70 \%$ for minimal query coverage and sequence identity of at least $45 \%$.

\section{Results and Discussion}

\section{Identification of $\boldsymbol{P}$. aminophilus JCM 7686 Genes Linked to Methylotrophy}

$P$. aminophilus JCM 7686 was isolated in Japan from soil contaminated with $\mathrm{N}, \mathrm{N}$-dimethylformamide (DMF) as a strain able to utilize many $\mathrm{C} 1$ compounds (Figure S1) (Urakami et al., 1990). However, no further analysis regarding the methylotrophy of this strain was performed. In the initial stage of this study we confirmed that, besides DMF, JCM 7686 can utilize methylamine, dimethylamine, trimethylamine, and formamide. We also found that it is able to utilize methanol (Figure 1), which is contrary to the original observations of Urakami et al. (1990). To determine the genetic basis of these phenotypes we examined the JCM 7686 genome (Dziewit et al., 2014) for the presence of genes linked to C1 metabolism and we performed functional analysis of selected genes to confirm our predictions. The collected data permitted

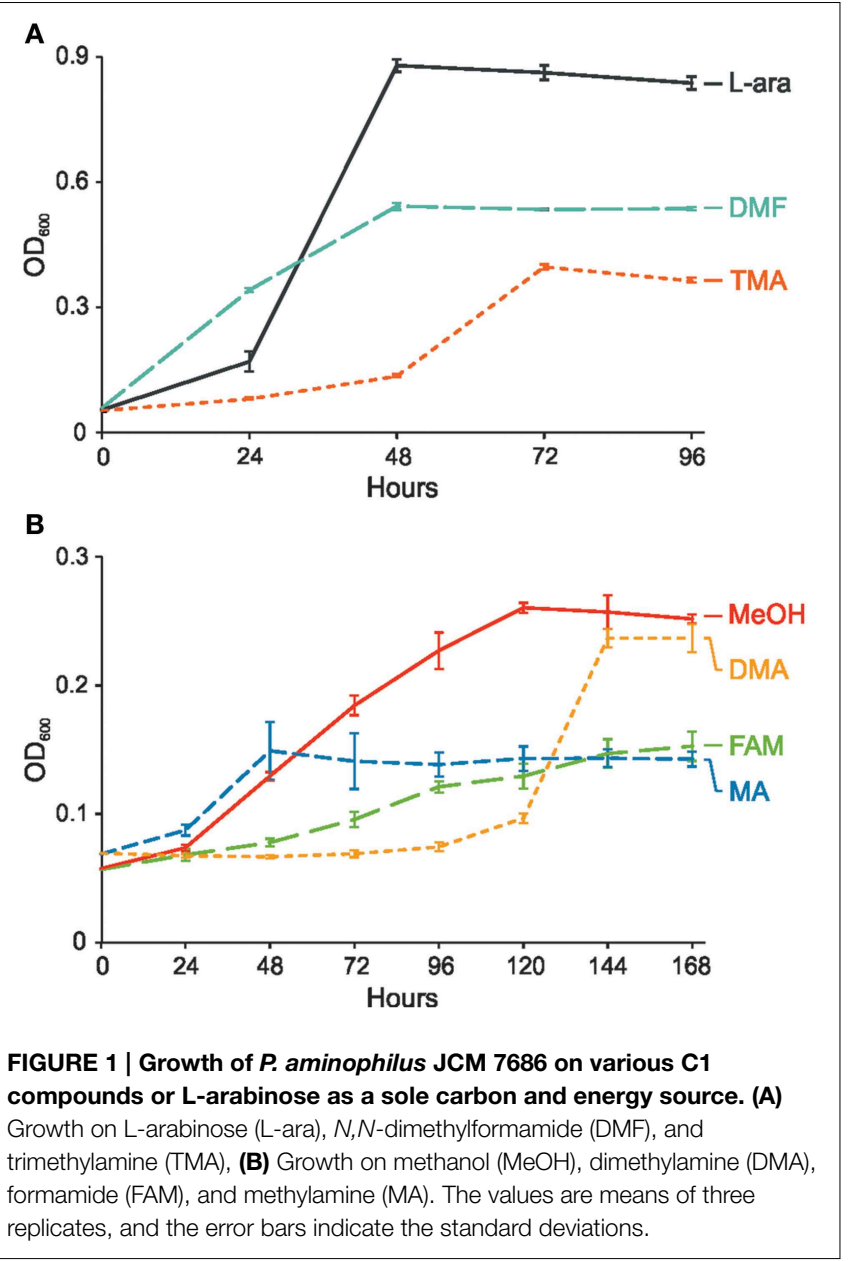

reconstruction of the complex $\mathrm{C} 1$ metabolic pathway of this strain (Figure 2, Table S4).

\section{Genes Involved in Methanol Utilization}

The ability of $P$. denitrificans Pd1222 to utilize methanol was shown to be dependent on the presence of mxa genes encoding i.a. subunits of a heterotetrameric PQQ-dependent calcium-binding $\mathrm{MeOH}$ dehydrogenase (MxaFI) (Van Spanning et al., 1991). Although $P$. aminophilus JCM 7686 is also able to oxidize $\mathrm{MeOH}$, the $m x a$ genes were not detected in this strain. Nevertheless, a gene encoding another type of $\mathrm{MeOH}$ dehydrogenase (xoxF; JCM7686_0090) was identified within the JCM 7686 chromosome. XoxF represents a group of homodimeric methanol dehydrogenases, related to the large subunit of MxaFI, which bind rare-earth elements instead of calcium (Keltjens et al., 2014). Interestingly, xoxF genes are widespread among both methylotrophs and nonmethylotrophic bacteria (Keltjens et al., 2014). Studies on Rhodobacter sphaeroides revealed that XoxF is required for methanol oxidation during both aerobic and anaerobic photosynthetic growth (Wilson et al., 2008).

The $P$. aminophilus-encoded XoxF belongs to the XoxF5 protein family (Keltjens et al., 2014). In the JCM 7686 chromosome, the $x o x F$ gene is clustered together with $x o x G$ 


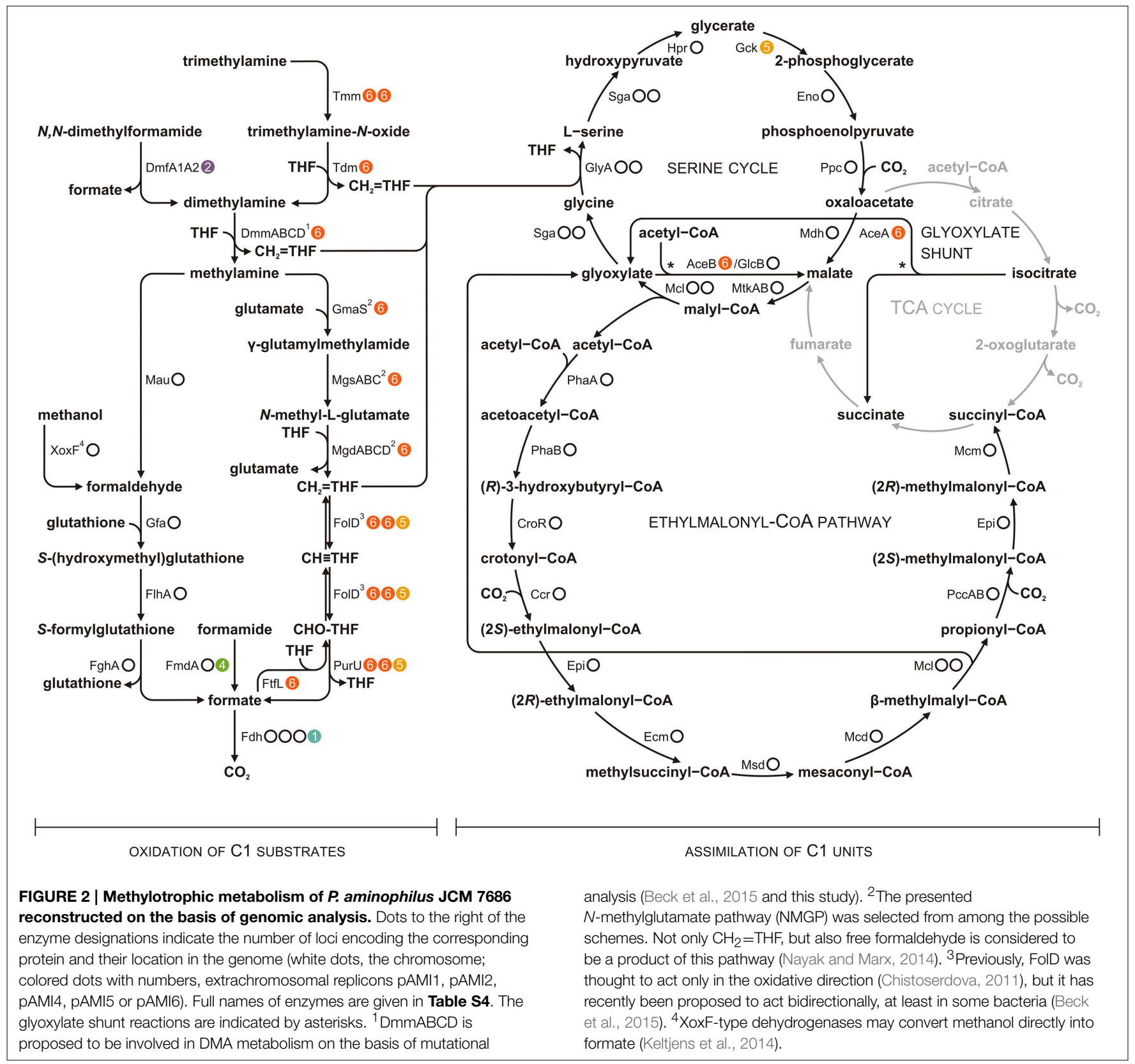

(JCM7686_0091, encoding a cytochrome c used as an electron acceptor for methanol oxidation) and xoxJ (JCM7686_0092, encoding a putative periplasmic binding protein), as well as with the genes of a glutathione-dependent formaldehyde dehydrogenase system (JCM7686_0085, JCM7686_0086, and JCM7686_0089) (Table S4). It suggests that formaldehyde, and not formate, is the product of methanol oxidation catalyzed by XoxF5 proteins (Keltjens et al., 2014). The clustering of $x o x F$ and the genes of the glutathione-dependent formaldehyde oxidation pathway is also seen in many other alphaproteobacterial genomes, e.g., in P. denitrificans Pd1222, Roseobacter litoralis Och 149, Dinoroseobacter shibae DFL 12 and Sinorhizobium fredii HH103 (Keltjens et al., 2014 and this study).
To evaluate the role of the identified $x o x F$ gene in methanol utilization, its mutational analysis was performed. This revealed that a strain with disrupted $x o x F$ was unable to grow in minimal medium with methanol as the sole source of carbon. The wildtype phenotype was restored when the $x o x F$ gene cloned in vector pBBR1MCS-3 was introduced into the mutant cells (Figure 3). This confirmed that XoxF is the enzyme responsible for methanol oxidation in P. aminophilus JCM 7686.

\section{Genes Involved in Utilization of Methylated Amines}

Three gene clusters, potentially involved in the utilization of TMA, DMA and MA as carbon, nitrogen and energy sources were identified in the $P$. aminophilus genome. Two of them are 


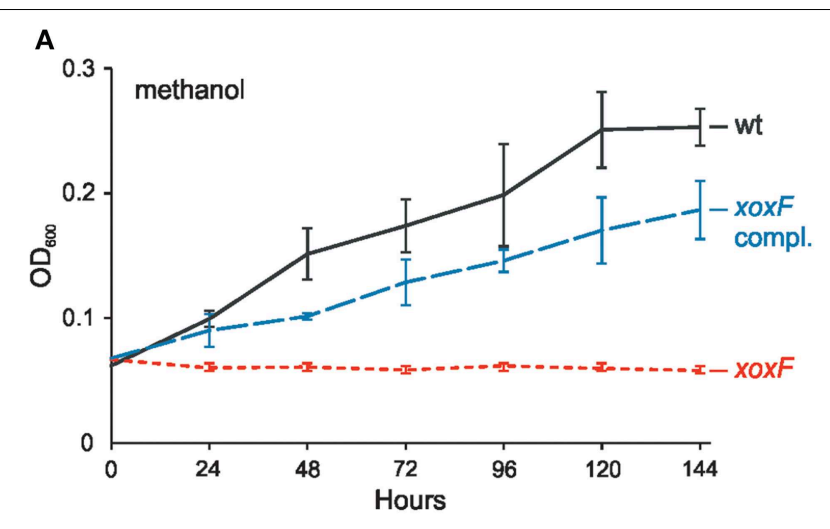

B

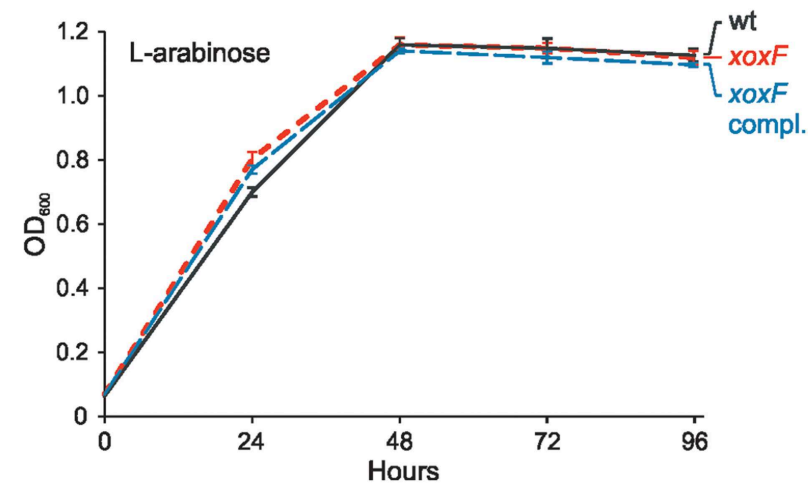

FIGURE 3 | Effect of the xox $F$ mutation on growth of $P$. aminophilus JCM 7686 on methanol (A) and L-arabinose (B). wt, wild type; $x O X F, x O X F$ insertional mutant; XOXF compl., XOXF insertional mutant complemented with a copy of the XoXF gene cloned in pBBR1MCS-3. The values are means of three replicates, and the error bars indicate the standard deviations.

located within the chromid pAMI6 and contain genes encoding enzymes responsible for TMA oxidation via trimethylamine $N$ oxide (TMAO) and MA oxidation via $N$-methylglutamate. The third cluster is located within the chromosome and encodes methylamine dehydrogenase.

TMA oxidation via TMAO depends on the activity of three enzymes: (i) TMA monooxygenase, (ii) TMAO demethylase, and (iii) DMA monooxygenase. Interestingly, pAMI6 carries two genes, tmm1 (JCM7686_pAMI6p076) and tmm2 (JCM7686_pAMI6p102), encoding putative TMA monooxygenases. The predicted Tmm1 and Tmm2 proteins show high amino acid (aa) sequence similarity (75\%) to one another and share about $60 \%$ identity with the Tmm protein of Methylocella silvestris BL2 (Chen et al., 2011). To analyze the role of the tmm genes in the TMA metabolism of JCM 7686, three mutant strains were constructed lacking either $t m m 1$ or $t m m 2$, or both genes. The growth rate of the strains containing single mutations (tmm1 or tmm2) in minimal medium with TMA as the sole carbon and energy source was identical to that of the wild type strain (Figure 4). In contrast, the double mutant strain (tmm1tmm2) was no longer able to utilize TMA, but it still had the ability to grow on medium supplemented with DMA or MA (the products of TMA utilization) (Figure 4). The growth on TMA was restored when tmm1 or tmm2 gene cloned in vector pBBR1MCS-5 was introduced into the double mutant strain (data not shown). These results indicated that both identified $t \mathrm{~mm}$ genes encode enzymes with the same specificity and that they are both involved in the first stage of TMA metabolism. Additionally, the contribution of two tmm genes in TMA oxidation was confirmed by RT-qPCR. It was shown that transcript levels of both genes are increased in a similar degree during growth on TMA in comparison with non-methylotrophic conditions (Table 1).

Genes encoding TMAO demethylase $(t d m$, JCM7686_pAMI6p069) and DMA monooxygenase ( $\mathrm{dmmDABC}$, JCM7686_pAMI6p074-71) were identified in the vicinity of tmm1. The predicted Tdm of $P$. aminophilus shares $63 \%$ aa sequence identity with the Tdm protein of Ruegeria pomeroyi DSS-3 (Lidbury et al., 2014) and the DmmDABC proteins are homologous to four subunits of the putative DMA monooxygenase of Methylocella silvestris BL2 (Zhu et al., 2014). The DmmC proteins of strains JCM 7686 and BL2 share $66 \%$ aa sequence identity, while the three other putative DMA subunits encoded by these strains (DmmA, DmmB, and DmmD) are less well-conserved $(39,41$, and $37 \%$ aa sequence identity, respectively).

To verify the function of the $P$. aminophilus $d m m D A B C$ genes, their mutational analysis was performed. The four mutant strains carrying deletions of the individual $\mathrm{dmm}$ genes failed to grow on dimethylamine as the sole carbon and energy source, while they showed the same growth rate as the wild-type strain when cultivated on methylamine or L-arabinose (Figure 5). The wild-type phenotype was restored when the $d m m D A B C$ module cloned in vector $\mathrm{pBBR} 1 \mathrm{MCS}-3$ was introduced into the mutant strains (data not shown). The mutations also influenced growth on $\mathrm{C} 1$ compounds that are metabolized via DMA, i.e., N,N-dimethylformamide and trimethylamine (Figure 5). Interestingly, inactivation of $d m m D$ had a much weaker effect on growth on TMA than the inactivation of the other $d m m$ genes (Figure 5). This observation is consistent with the hypothesis that the DmmD protein is not necessary for the conversion of DMA into MA and formaldehyde, but is an auxiliary subunit of the DMA monooxygenase which may convert formaldehyde into methylene-THF (Zhu et al., 2014).

Methylamine (MA), which is the product of DMA utilization, is presumably oxidized by $P$. aminophilus via two different pathways. Upstream and downstream of tmm2, we identified genes responsible for MA oxidation via $N$-methylglutamate (the $N$-methylglutamate pathway for MA oxidation, NMGP). They are arranged in two putative operons encoding three enzymes of the pathway: (i) the mgsABC-gmaS operon (JCM7686_pAMI6p108-105) encoding glutamate-MA ligase (GmaS) and $N$-methyl-L-glutamate synthase (MgsABC), and (ii) the $m g d A B C D$ operon (JCM7686_pAMI6p099-096) encoding $N$ methyl-L-glutamate dehydrogenase (MgdABCD). Most of the NMGP enzymes subunits show high levels of aa sequence identity with the respective proteins of $M$. silvestris BL2 (Chen et al., 2010).

The second $P$. aminophilus pathway responsible for MA oxidation relies on the activity of a two-subunit MA dehydrogenase (Mau). Genes encoding this enzyme are 


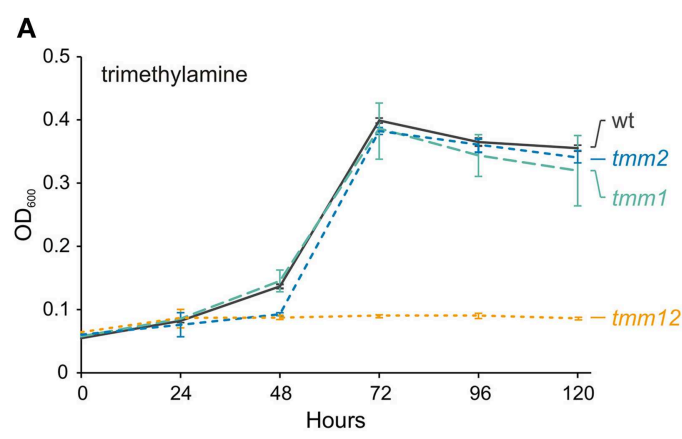

C

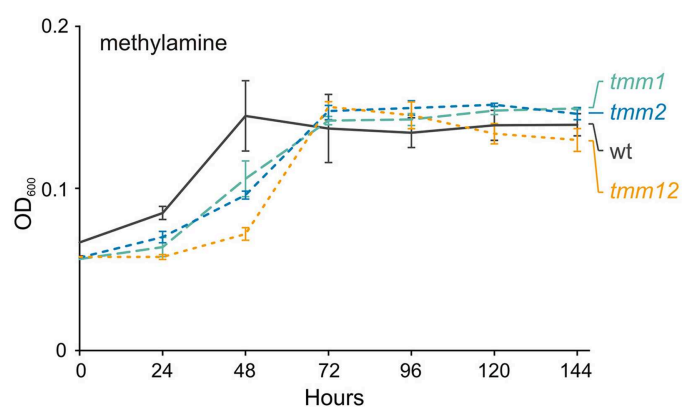

FIGURE 4 | Effect of the tmm1 and tmm2 mutations on growth of $P$. aminophilus JCM 7686 on trimethylamine (A), dimethylamine (B), methylamine (C), and L-arabinose (D). wt, wild type; $t m m 1$, $t m m 1$

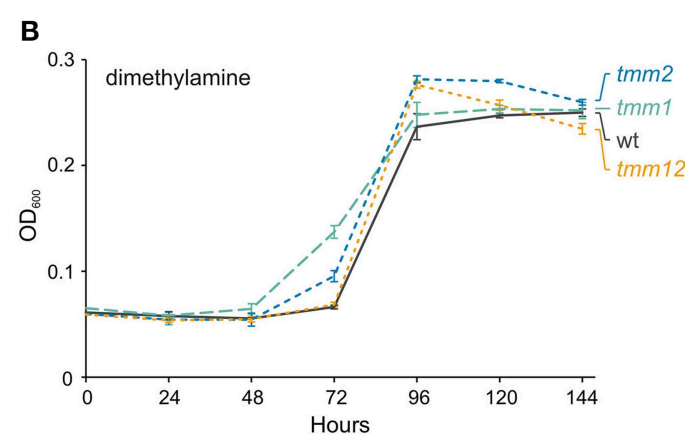

D

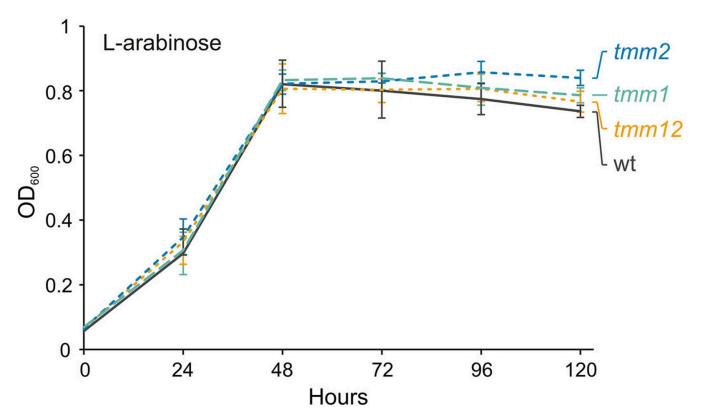

insertional mutant; tmm2, tmm2 insertional mutant; tmm12, double insertional mutant in tmm 1 and $t m m 2$ genes. The values are means of three replicates, and the error bars indicate the standard deviations.
TABLE 1 | Changes in the transcript levels of selected methylotrophy genes of $P$. aminophilus JCM 7686 in methylotrophic vs. non-methylotrophic conditions determined by RT-qPCR analysis.

\begin{tabular}{lllr}
$\begin{array}{l}\text { ORF } \\
\text { name }\end{array}$ & Protein name & Process & $\begin{array}{c}\text { Fold change } \\
\mathbf{\pm} \mathbf{S D}^{*}\end{array}$ \\
\hline tmm1 & TMA monooxygenase & oxidation of TMA & $26.7 \pm 2.8$ \\
tmm2 & TMA monooxygenase & oxidation of TMA & $27.3 \pm 1.9$ \\
hpr & hydroxypyruvate reductase & serine cycle & $3.0 \pm 1.0$ \\
gck & glycerate 2-kinase & serine cycle & $5.9 \pm 0.7$ \\
aceA & isocitrate lyase & glyoxylate shunt & $13.5 \pm 2.6$ \\
ecm & ethylmalonyl-CoA mutase & ethylmalonyl-CoA pathway & $4.9 \pm 0.6$ \\
$\mathrm{mcm}$ & methylmalonyl-CoA mutase & ethylmalonyl-CoA pathway & $4.6 \pm 1.0$ \\
\hline
\end{tabular}

${ }^{*} \mathrm{SD}$, standard deviation.

arranged in a large chromosomal cluster (JCM7686_0162-0171, mauFBEDACJGMN). This gene cluster is very similar to the mau region located in plasmid 1 of $P$. denitrificans $\mathrm{Pd} 1222$ (approximately 75\% nucleotide sequence identity) (van Der Palen et al., 1995). The mau genes are crucial for growth of P. denitrificans Pd1222 on MA (van Der Palen et al., 1995). However, in $P$. aminophilus we found that mutation of the gene encoding the catalytic subunit MauA did not abolish growth on this compound. In this case, the growth rate on MAcontaining medium was reduced (Figure S2), which indicated that both identified pathways for MA utilization are active in P. aminophilus.

\section{Genes Involved in Utilization of Formamides}

Strain JCM 7686 can also utilize formamides, including $\mathrm{N}, \mathrm{N}$ dimethylformamide (Figures 1, 2). Formamide breakdown is most probably catalyzed by two chromosomally- and pAMI4-encoded acetamidases/formamidases (JCM7686_1450, JCM7686_pAMI4p036), while DMF utilization is dependent on a pAMI2-encoded $\mathrm{N}, \mathrm{N}$-dimethylformamidase (DMFase) (JCM7686_pAMI2p015-017). The latter assumption was confirmed in our previous study in which we found that $P$. aminophilus strain deprived of pAMI2 was unable to utilize DMF (Dziewit et al., 2010). Plasmid pAMI2 carries genes encoding two subunits of DMFase (DmfA1 and DmfA2) which are organized in an operon. More detailed studies revealed that the expression of these genes is activated in the presence of DMF by the LuxR-family transcriptional activator DmfR (Dziewit et al., 2010). Interestingly, a related $d m f A 1-d m f A 2$ locus (encoding predicted proteins sharing $34 \%$ and $40 \%$ aa sequence identity with DmfA1 and DmfA2 of pAMI2, respectively) was also identified within chromid pAMI5 (JCM7686_pAMI5p063-064). However, these genes have not been found to be linked to DMF utilization.

\section{Genes Involved in Oxidation of Formaldehyde and $\mathrm{CH}_{2}=\mathrm{THF}$ to $\mathrm{CO}_{2}$ and Reduction of Formate to $\mathrm{CH}_{2}=$ THF}

Most of the aforementioned pathways of $\mathrm{C} 1$ substrate oxidation result in the formation of formaldehyde and/or $\mathrm{CH}_{2}=\mathrm{THF}$ (Chistoserdova, 2011; Keltjens et al., 2014; Lidbury et al., 


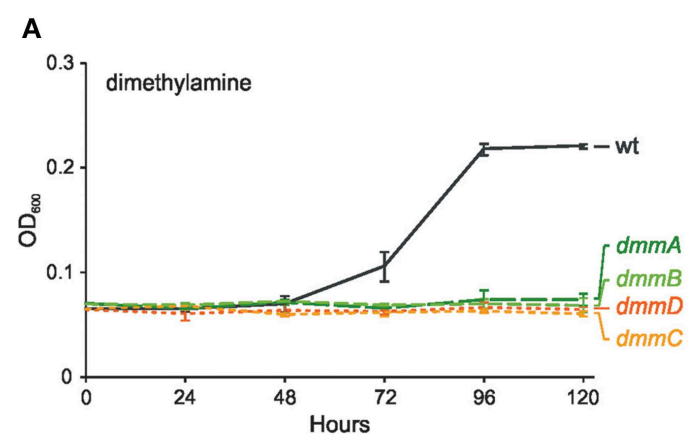

C

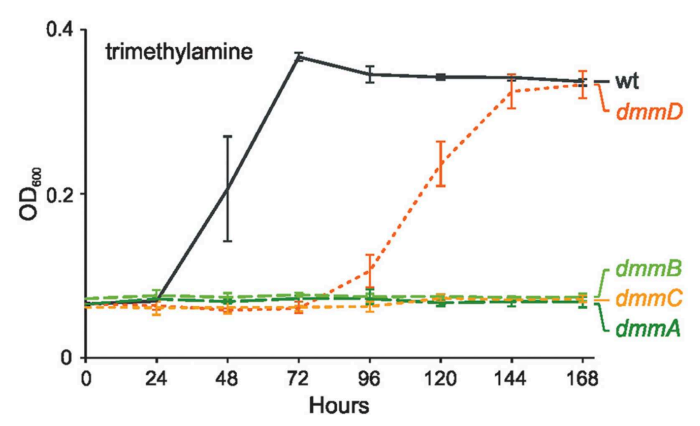

E

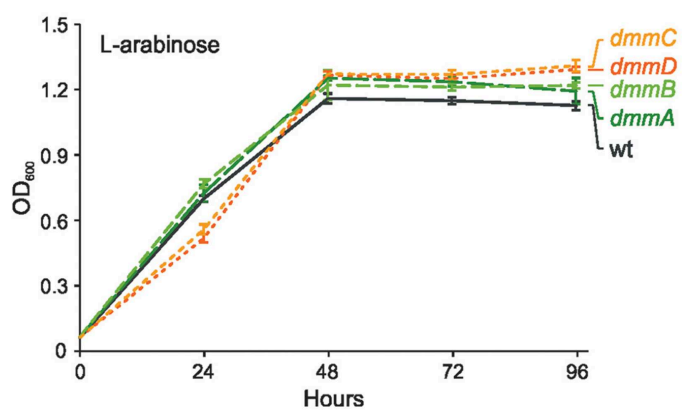

FIGURE 5 | Effect of mutations in genes encoding four putative subunits of dimethylamine monooxygenase (dmmDABC) on growth of $P$. aminophilus JCM 7686 on dimethylamine (A), $\mathrm{N}, \mathrm{N}$-dimethylformamide (B), trimethylamine (C), methylamine (D),

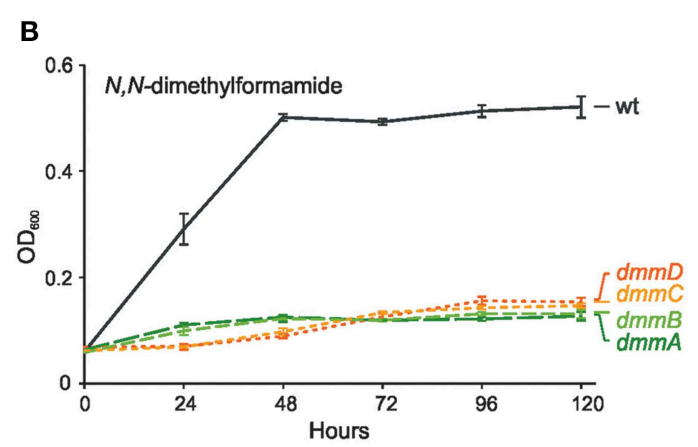

D

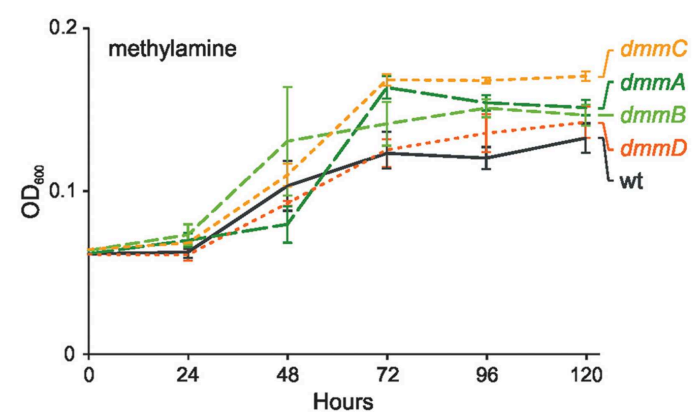

and L-arabinose (E). wt, wild type; $d m m A, d m m A$ insertional mutant; $d m m B, d m m B$ insertional mutant; $d m m C, d m m C$ insertional mutant; $d m m D, d m m D$ insertional mutant. The values are means of three replicates, and the error bars indicate the standard deviations.
2014; Nayak and Marx, 2014) (Figure 2). In P. aminophilus JCM 7686, the oxidation of formaldehyde to formate is most likely achieved via the glutathione-dependent pathway utilizing three chromosomally encoded enzymes: (i) $S$ (hydroxymethyl)glutathione synthase (Gfa, JCM7686_0085), (ii) $S$-(hydroxymethyl)glutathione dehydrogenase (FlhA, JCM7686_0086), and (iii) S-formylglutathione hydrolase (FghA, JCM7686_0089). Each of these enzymes shares a high level of aa sequence identity $(\sim 85 \%)$ with the corresponding protein from $P$. denitrificans Pd1222. It is worth noting that the $S$ (hydroxymethyl)glutathione dehydrogenase was previously recognized as essential for methylotrophic growth of $P$. denitrificans (Ras et al., 1995).

$P$. aminophilus JCM 7686 encodes enzymes involved in transitions between $\mathrm{CH}_{2}=\mathrm{THF}$ and formate in both the oxidizing and reducing directions. The oxidation of the methylene group of $\mathrm{CH}_{2}=\mathrm{THF}$ is associated with energy release, while the reductive pathway is required to supply $\mathrm{CH}_{2}=\mathrm{THF}$ to the serine cycle (see below) during growth of $P$. aminophilus on methanol and formamide (i.e., $\mathrm{C} 1$ compounds, whose oxidation leads to the formation of formaldehyde or formate but not $\mathrm{CH}_{2}=\mathrm{THF}$ ) (Figure 2).

Oxidation of the methylene group to formate is performed by the action of two enzymes: $\mathrm{CH}_{2}=\mathrm{THF}$ dehydrogenase $/ \mathrm{CH}_{2}=\mathrm{THF}$ cyclohydrolase (FolD) and formyltetrahydrofolate deformylase (PurU). FolD and PurU are encoded by three homologous two-gene loci (folD-purU) located in pAMI6 (2 loci) and pAMI5 (Table S4). In the reduction pathway, formate is loaded into THF by formatetetrahydrofolate ligase (FtfL, JCM7686_pAMI6p042) and then 
reduced to the methylene group. In many methylotrophs (e.g., Methylobacterium extorquens) the reduction process is performed by the sequential action of two enzymes: $\mathrm{CH}_{2}=\mathrm{THF}$ cyclohydrolase $(\mathrm{Fch})$ and $\mathrm{CH}_{2}=$ THF dehydrogenase (MtdA) (Chistoserdova, 2011). Since P. aminophilus encodes neither Fch nor MtdA, the reduction of 10 -formyl-THF to $\mathrm{CH}_{2}=\mathrm{THF}$ is presumably catalyzed by FolD which seems to work bi-directionally in some bacteria (Beck et al., 2015).

The product of oxidation of formaldehyde and the methylene group of $\mathrm{CH}_{2}=\mathrm{THF}$ is formate. It is further oxidized to $\mathrm{CO}_{2}$ by formate dehydrogenase (Fdh) (Chistoserdova et al., 2004). In the $P$. aminophilus genome there are four gene clusters encoding formate dehydrogenases; three of them are located in the chromosome (JCM7686_0639-0643, JCM7686_2088, JCM7686_3476-3480) and one in plasmid pAMI1 (JCM7686_pAMI1p027).

\section{Genes Involved in Assimilation of C1 Units}

In contrast to other methylotrophic strains of the genus Paracoccus, P. aminophilus JCM 7686 is unable to grow autotrophically using the Calvin cycle. The genome of this strain does not encode subunits of the key enzyme of this process, ribulose-1,5-bisphosphate carboxylase/oxygenase (RuBisCO). Therefore, the only possible way to assimilate $\mathrm{C} 1$ compounds seems to be via the serine cycle. P. aminophilus carries a chromosomally encoded cluster of serine cycle genes, which is also highly conserved in the genome of Paracoccus sp. N5 (Beck et al., 2015). Since many of these genes encode proteins that are highly divergent from the well-studied serine cycle enzymes of other methylotrophs (Beck et al., 2015), functional analysis was required to confirm their specific activities.

The serine cycle gene cluster of $P$. aminophilus is incomplete since it does not contain a gck gene encoding glycerate 2-kinase, which is, surprisingly, present at a different genomic locationwithin chromid pAMI5. Interestingly, the Gck of P. aminophilus is more closely related to a protein from the marine bacterium Labrenzia alexandrii DFL-11 ( $72 \%$ aa sequence identity) than to the Gck of Paracoccus sp. N5 (38\% aa sequence identity) and other homologous genes found in Paracoccus spp., which strongly suggests that the JCM 7686 gck gene was independently acquired by horizontal gene transfer.

The serine cycle cannot operate without regeneration of glyoxylate from acetyl-CoA, which can proceed via the glyoxylate shunt or the ethylmalonyl-CoA pathway (EMCP) (Chistoserdova, 2011). Both pathways also enable growth on C2 compounds. The chromosome of $P$. aminophilus contains the genetic information required for the synthesis of all enzymes of the EMCP (Table S4). Moreover, pAMI6 contains a two-gene locus (JCM7686_pAMI6p120-121) encoding putative enzymes of the glyoxylate shunt: isocitrate lyase (AceA) and malate synthase (AceB). An additional copy of the gene encoding malate synthase (malate synthase G, GlcB, JCM7686_1627) was identified within the chromosome of this strain. Therefore, our bioinformatic sequence analysis indicates that $P$. aminophilus may regenerate glyoxylate via both the EMCP and glyoxylate shunt.

We performed RT-qPCR analyses to confirm that the predicted serine cycle genes ( $h p r$ carried within pAMI6 and gck carried within pAMI5), the gene of isocitrate lyase (aceA) involved in the glyoxylate shunt, as well as two genes of the ethylmalonyl-CoA pathway $(\mathrm{ecm}$ and $\mathrm{mcm}$ ) are linked to methylotrophic metabolism of the JCM 7686 strain. The results showed that in each case the transcript level was elevated during methylotrophic growth (Table 1).

\section{Abundance of Methylotrophy-linked Genes in Paracoccus spp. Genomes}

Annotated genomic sequences of 17 strains of Paracoccus spp. (including $P$. aminophilus JCM 7686) are currently available in the GenBank database (Figure 6). The genomes of these strains were screened for the presence of 67 genes encoding enzymes involved in methylotrophy that have been identified in P. aminophilus and other methylotrophic Alphaproteobacteria. It is important to note that for 15 Paracoccus spp. strains only draft genomes were available, thus some data may be missing. Therefore, the lack of the particular genes has to be verified after obtaining complete genome sequences of those strains.

On the basis of the performed analysis, strains of Paracoccus spp. were classified into four groups: (i) autotrophic methylotrophs, which can potentially assimilate $\mathrm{CO}_{2}$ via the Calvin cycle (six strains), (ii) facultatively autotrophic methylotrophs, which have both the serine cycle and the Calvin cycle (3 strains), (iii) heterotrophic methylotrophs, which use only the serine pathway for carbon assimilation, represented only by P. aminophilus JCM 7686, and (iv) non-methylotrophs (Figure 6).

More differences were observed when the strains were compared in terms of the range of $\mathrm{C} 1$ compounds that potentially can be oxidized. All but one strain (P. halophilus JCM 14014) encode XoxF methanol dehydrogenase, and six strains $(P$. denitrificans Pd1222, P. pantotrophus J40, J46 and Paracoccus spp. J39, J55, TRP) also encode a PQQ-dependent calciumbinding methanol dehydrogenase (MxaFI) (Figure 6). Eight of the analyzed strains encode enzymes responsible for the utilization of methylated amines. Of these, five (JCM 7686, J39, J55, N5, and ATCC BAA-599) also encode enzymes that are required for trimethylamine oxidation via trimethylamine $N$-oxide. In addition, these five strains plus $P$. versutus DSM 582 possess $d m m A B C D$ genes encoding putative dimethylamine monooxygenase (Figure 6).

Another interesting observation was made while analyzing genes involved in methylamine utilization. Three groups of strains were distinguished that are likely to be able to perform methylamine oxidation via different routes: (i) the NMGP (all facultatively autotrophic methylotrophs, i.e., Paracoccus sp. J39, J55, and N5), (ii) the pathway involving Mau (P. denitrificans Pd1222 and Paracoccus sp. TRP), and (iii) both pathways ( $P$. aminophilus, P. yeei, and P. versutus) (Figure 6).

What is noteworthy, in all strains possessing the serine cycle genes, a co-occurrence of the genes involved in TMA oxidation via TMAO and the NMGP was observed. In P. aminophilus JCM 7686, these genes are present within three separate clusters. Two of them are located in pAMI6 (genes involved in TMA oxidation and in the NMGP) and the other (involved in the serine cycle) in the chromosome (Figure 7). In Paracoccus sp. 


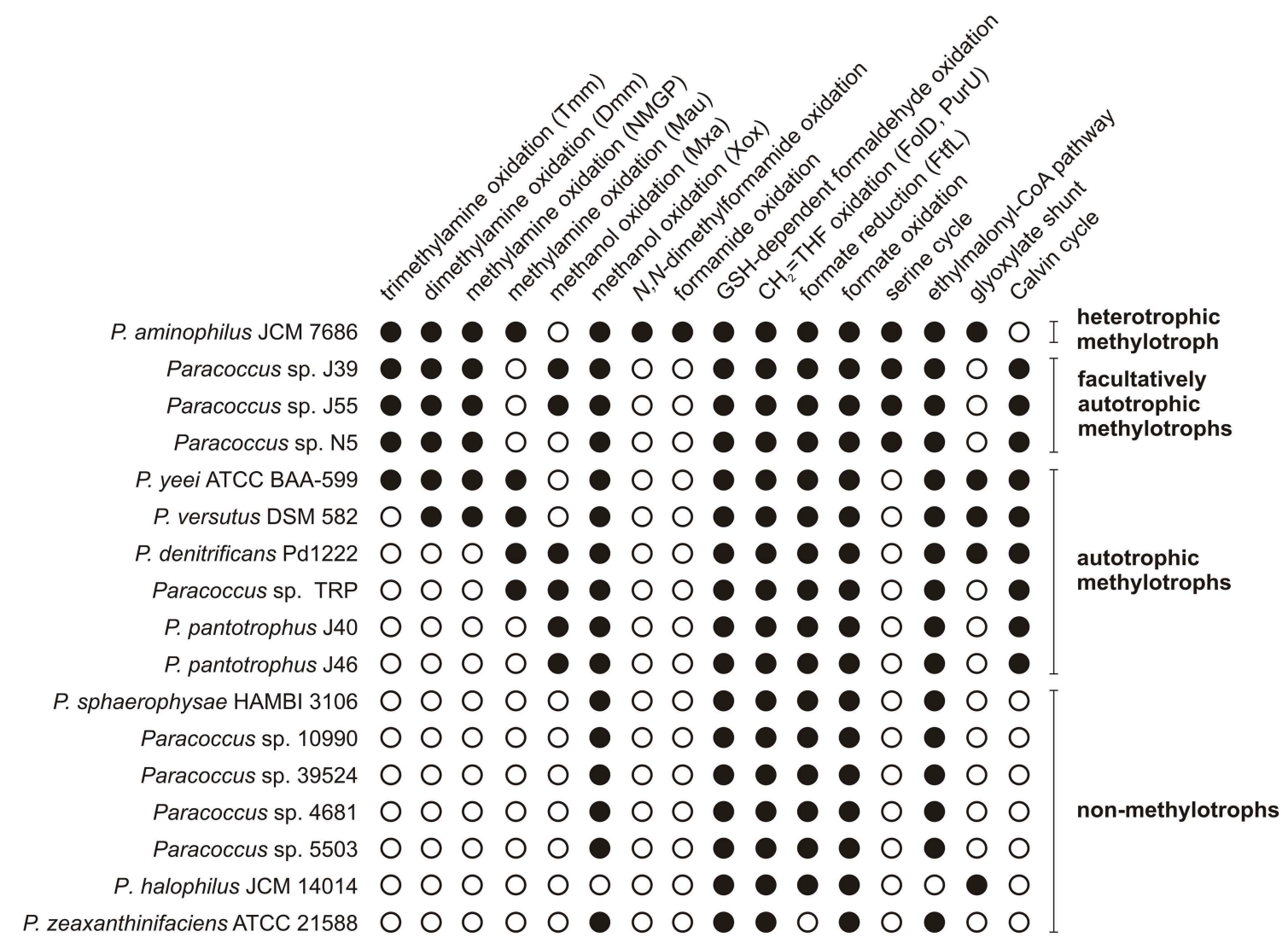

FIGURE 6 | The methylotrophy-linked metabolic capabilities encoded by the genomes of Paracoccus spp. Tmm, trimethylamine monooxygenase; Dmm, putative dimethylamine monooxygenase; NMGP, $N$-methylglutamate pathway; Mau, methylamine dehydrogenase; Mxa, Mxa-type methanol dehydrogenase; Xox, Xox-type methanol dehydrogenase; GSH, glutathione; $\mathrm{CH}_{2}=\mathrm{THF}, 5,10$-methylenetetrahydrofolate; FolD, 5,10-methylene-tetrahydrofolate dehydrogenase/5,10-methylene-tetrahydrofolate cyclohydrolase; PurU, formyltetrahydrofolate deformylase; FtfL, formate-tetrahydrofolate ligase. The accession numbers of Paracoccus complete genomes: JCM7686 GQ410978, GQ468939, GQ468938, CP006650-CP006655, and Pd1222 -
CP000489-CP000491. The accession numbers of Paracoccus draft genomes: J39 - JAEN01000001-JAEN01000050, J55 AZVA01000001-AZVA01000069, N5 - AQU001000001-AQU001000003, ATCC BAA-599 - JHWH01000001- JHWH01000073, DSM 582 JRKO01000001- JRK001000187, TRP - AEPN01000001AEPN01000119, J40 - JAGK01000001- JAGK01000119, J46 JAEM01000001- JAEM01000105, HAMBI 3106 - JRKS01000001JRKS01000137, 10990 - JRKR01000001- JRKR01000309, 39524 JRKP01000001-JRKP01000273, 4681 - JRKT01000001- JRKT01000176, 5503 - JRKQ01000001- JRKQ01000265, JCM 14014 - JRKN01000001JRKN01000122, and ATCC 21588 - ATUJ01000001- ATUJ01000035.
N5 all the aforementioned genes form a single methylotrophy island, which is most probably extrachromosomally located (Figure 7).

Interestingly, we found that the gene clusters homologous with the methylotrophy island of Paracoccus sp. N5 are also present in the chromosomes of numerous strains of the marine Roseobacter clade (Figure 7), many of which were recognized as serine cycle methylotrophs (Newton et al., 2010). These bacteria comprise up to $20 \%$ of the microorganisms in coastal surface waters (Chen, 2012). Therefore, the identified methylotrophy islands may constitute one of the most abundant sets of genes participating in $\mathrm{C} 1$ metabolism worldwide. Since these islands contain genes involved in all three stages of the methylotrophy process (oxidation of specific $\mathrm{C} 1$ substrates, oxidation of $\mathrm{CH}_{2}=\mathrm{THF}$ and assimilation of C1 units), their transfer to other hosts may result in the conversion of non-methylotrophic strains into methylotrophs.
It is noteworthy that bacteria of the Roseobacter clade are well known for the presence of numerous conjugative megaplasmids, which may promote horizontal transmission of large segments of genomic DNA (Petersen et al., 2012, 2013).

In the case of $P$. aminophilus JCM 7686 several other extrachromosomal elements besides pAMI6 (plasmids pAMI1, pAMI2, pAMI4, and chromid pAMI5) contain genes linked to methylotrophy. As previously shown (Dziewit et al., 2014), the host range of these elements is not limited to Paracoccus spp. and extends to other strains of Alphaproteobacteria, including Agrobacterium tumefaciens and Rhizobium etli. Thus, further transfer of these extrachromosomally-located methylotrophy genes to other hosts may result in the formation of "patchwork" methylotrophic pathways and the generation of bacterial strains with novel metabolic properties. 
PARACOCCUS SPP.
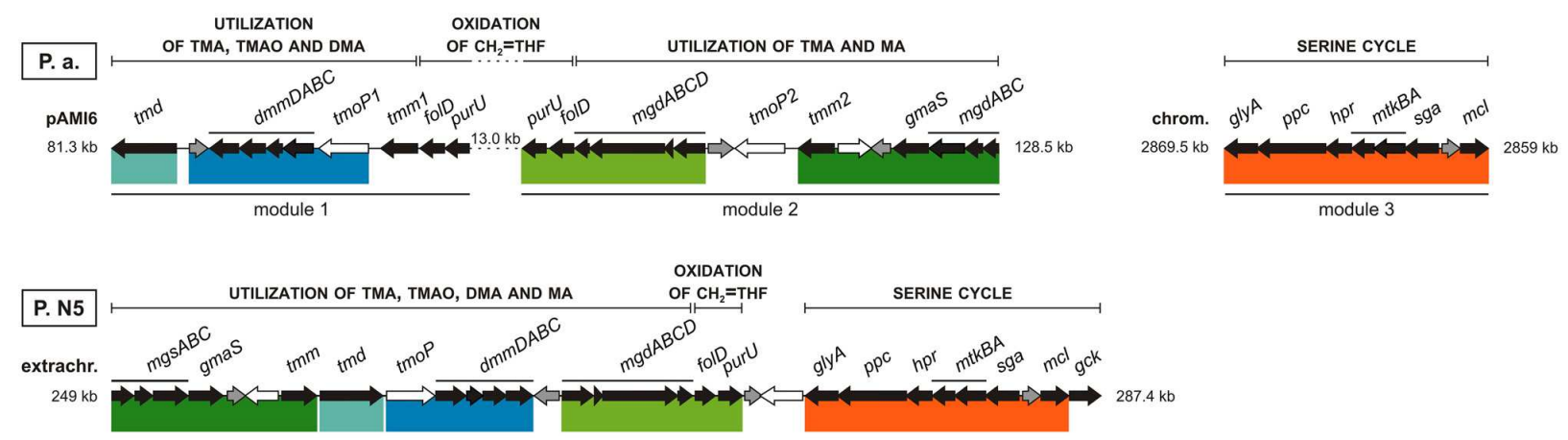

ROSEOBACTER CLADE
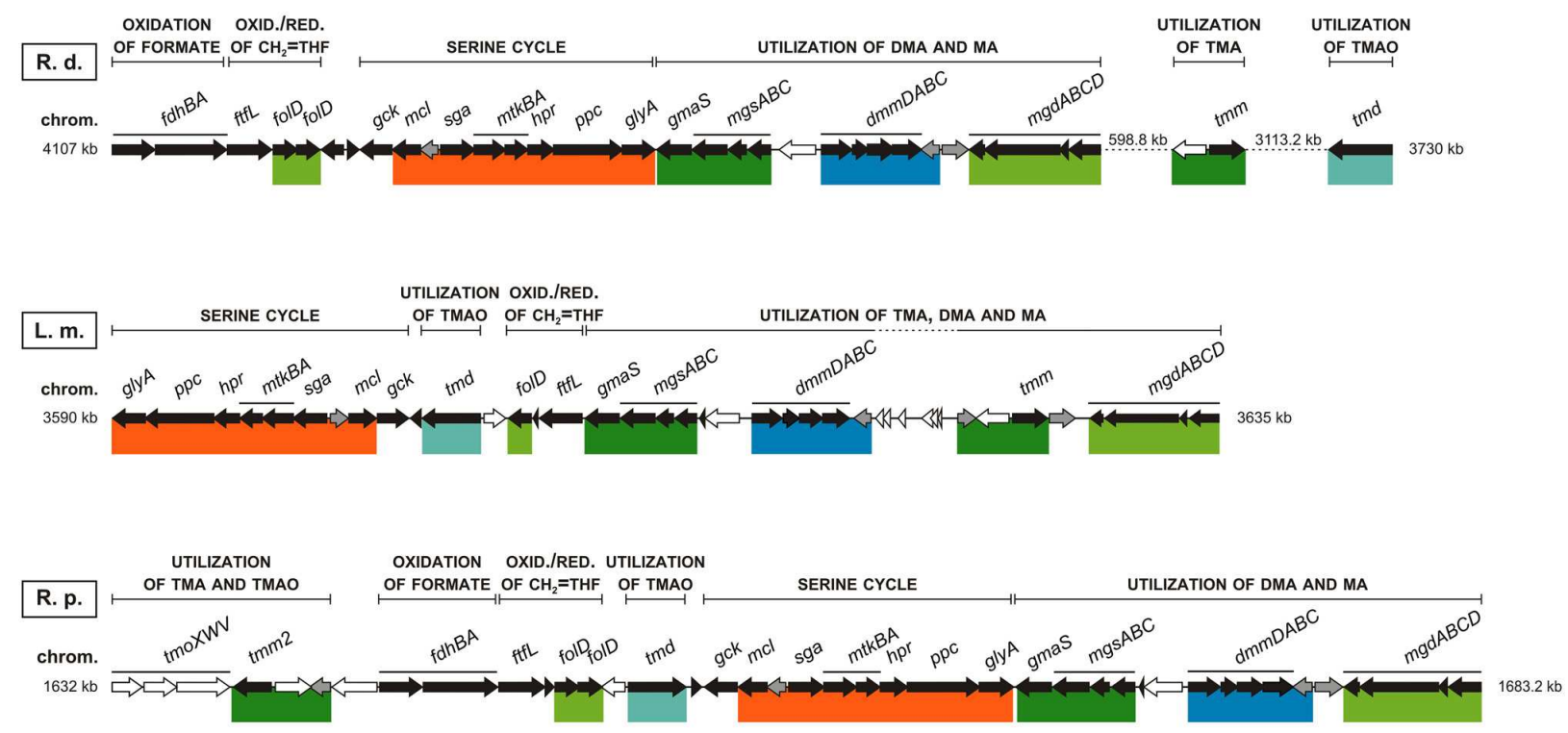

AbBreviations

$\begin{array}{ll}\text { oxid. } & \text { oxidation } \\ \text { red. } & \text { reduction } \\ \text { chrom. } & \text { chromosome } \\ \text { extrachr. } & \text { putative extrachromosomal } \\ & \text { replicon }\end{array}$

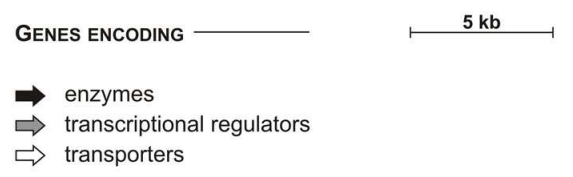

$\begin{array}{llll}\text { P. a. } & \text { Paracoccus aminophilus JCM } 7686 & \text { oxid. } & \text { oxidation } \\ \text { P. N5 } & \text { Paracoccus sp. N5 } & \text { red. } & \text { reduction } \\ \text { R. d. Roseobacter denitrificans Och } 114 & \text { chrom. } & \text { chromosome } \\ \text { L. m. Leisingera methylohalidivorans DSM } 14336 & \text { extrachr. } & \text { putative extrachromosomal } \\ \text { R. p. Ruegeria pomeroyi DSS-3 } & & \text { replicon }\end{array}$

$\Rightarrow$ transcriptional regulators

$\Rightarrow$ transporters

FIGURE 7 | Comparison of clustering of the serine pathway genes with other methylotrophy-linked genes in P. aminophilus JCM 7686, Paracoccus sp. N5, and three selected strains of the Roseobacter clade. Colored bars show shuffling of specific DNA regions when compared to $P$. aminophilus JCM 7686. In $P$. aminophilus JCM 7686, the presented set of methylotrophy genes is divided into three clusters, two located within PAMI6 and one within the chromosome. In the other strains all these genes constitute a single methylotrophy island, which may be located within the chromosome (R. pomeroyi DSS-3 and $L$. methylohalidivorans DSM 14336), or in putative extrachromosomal

replicons (Paracoccus sp. N5). In some cases, certain genes of the methylotrophy island may be found in a distant location in a genome (e.g., the tmm and tdm genes of $R$. denitrificans Och 114). The full names of enzymes encoded by most of the genes presented in the figure are summarized in Table S4. The others are tmoP-TMAO permease gene (Zhu et al., 2014), and tmoXWV-TMAO ABC-transporter system genes (Lidbury et al., 2014). The accession numbers of particular replicons are as follows: JCM 7686 - CP006654 (pAMI6) and CP006650 (chromosome), N5 - AQU001000003, Och 114 - CP000362, DSM 14336 - CP006773, DSS-3 - CP000031. 


\section{Conclusions}

The major goal of this study was to define the metabolic network involved in the $\mathrm{C} 1$ metabolism of $P$. aminophilus JCM 7686 and to compare it at the genetic level with other members of the genus Paracoccus. A genome-wide analysis revealed the great methylotrophic potential of this strain, manifested in its ability to utilize a wide range of $\mathrm{C} 1$ compounds, including formamide and $\mathrm{N}, \mathrm{N}$-dimethylformamide. These phenotypes enabled adaptation of $P$. aminophilus to its natural "methylotrophic" habitat, which was soil contaminated with DMF.

On the basis of the in silico and experimental evidence we defined complex methylotrophic pathways of $P$. aminophilus, with by-pass pathways for methylamine utilization and genes encoding multiple enzymes of the same specificity involved e.g., in trimethylamine utilization. The analysis revealed that this strain is the only known heterotrophic methylotroph among Paracoccus spp., encoding enzymes of the serine cycle as an exclusive pathway for $\mathrm{C} 1$ unit assimilation. Thus, $P$. aminophilus JCM 7686 is an excellent model for the studies on genetic diversity and evolution of methylotrophy in this group of bacteria.

\section{Acknowledgments}

We acknowledge J. Baj for helpful discussions and advice, L. Kowalski and K. Kuzmicz for technical assistance, and

\section{References}

Altschul, S. F., Madden, T. L., Schäffer, A. A., Zhang, J., Zhang, Z., Miller, W., et al. (1997). Gapped BLAST and PSI-BLAST: a new generation of protein database search programs. Nucleic Acids Res. 25, 3389-3402. doi: 10.1093/nar/25. 17.3389

Baker, S. C., Ferguson, S. J., Ludwig, B., Page, M. D., Richter, O. M., and van Spanning, R. J. (1998). Molecular genetics of the genus Paracoccus: metabolically versatile bacteria with bioenergetic flexibility. Microbiol. Mol. Biol. Rev. 62, 1046-1078.

Bartosik, D., Baj, J., Bartosik, A. A., and Wlodarczyk, M. (2002). Characterization of the replicator region of megaplasmid pTAV3 of Paracoccus versutus and search for plasmid-encoded traits. Microbiology 148, 871-881. doi: 10.1099/ 00221287-148-3-871

Bartosik, D., Szymanik, M., and Wysocka, E. (2001). Identification of the partitioning site within the repABC-type replicon of the composite Paracoccus versutus plasmid pTAV1. J. Bacteriol. 183, 6234-6243. doi: 10.1128/JB.183.21.6234-6243.2001

Beck, D. A., McTaggart, T. L., Setboonsarng, U., Vorobev, A., Goodwin, L., Shapiro, N., et al. (2015). Multiphyletic origins of methylotrophy in Alphaproteobacteria, exemplified by comparative genomics of Lake Washington isolates. Environ. Microbiol. 17, 547-554. doi: 10.1111/1462-2920. 12736

Caspi, R., Foerster, H., Fulcher, C. A., Kaipa, P., Krummenacker, M., Latendresse, M., et al. (2008). The MetaCyc Database of metabolic pathways and enzymes and the BioCyc collection of pathway/genome databases. Nucleic Acids Res. 36, D623-D631. doi: 10.1093/nar/gkm900

Chen, Y. (2012). Comparative genomics of methylated amine utilization by marine Roseobacter clade bacteria and development of functional gene markers (tmm, gmaS). Environ. Microbiol. 14, 2308-2322. doi: 10.1111/j.14622920.2012.02765.x
M. Puzyna for help in the preparation of the figures. This work was founded by the Ministry of Science and Higher Education, Poland (grant: IP2011 011471) and National Science Centre (NCN), Poland, on the basis of the decision number DEC-2013/09/B/NZ1/00133. The bioinformatics support of the BMBF-funded project "Bielefeld-Gießen Center for Microbial Bioinformatics-BiGi (grant: 031A533)" within the German Network for Bioinformatics Infrastructure (de.NBI) is gratefully acknowledged.

\section{Supplementary Material}

The Supplementary Material for this article can be found online at: http://journal.frontiersin.org/article/10.3389/fmicb. 2015.00852

\section{Figure $\mathrm{S} 1$ | Chemical structures of $\mathrm{C} 1$ compounds utilized by $P$ aminophilus JCM 7686 .}

Figure S2 | Effect of the mauA mutation on growth of $P$. aminophilus JCM 7686 on methylamine. wt, wild type; mauA, mauA insertional mutant. The values are means of three replicates, and the error bars indicate the standard deviations.

Table S1 | Bacterial strains used in this study.

Table S2 | Plasmids used and constructed in this study.

Table S3 | Oligonucleotide primers used in this study.

Table S4 | Genes of $P$. aminophilus JMC 7686 involved in the metabolism of $\mathrm{C} 1$ compounds.

Chen, Y., Patel, N. A., Crombie, A., Scrivens, J. H., and Murrell, J. C. (2011). Bacterial flavin-containing monooxygenase is trimethylamine monooxygenase. Proc. Natl. Acad. Sci. U.S.A. 108, 17791-17796. doi: 10.1073/pnas.111 2928108

Chen, Y., Scanlan, J., Song, L., Crombie, A., Rahman, M. T., Schäfer, H., et al. (2010). $\gamma$-Glutamylmethylamide is an essential intermediate in the metabolism of methylamine by Methylocella silvestris. Appl. Environ. Microbiol. 76, 4530-4537. doi: 10.1128/AEM.00739-10

Chistoserdova, L. (2011). Modularity of methylotrophy, revisited. Environ. Microbiol. 13, 2603-2622. doi: 10.1111/j.1462-2920.2011.02464.x

Chistoserdova, L., Laukel, M., Portais, J. C., Vorholt, J. A., and Lidstrom, M. E. (2004). Multiple formate dehydrogenase enzymes in the facultative methylotroph Methylobacterium extorquens AM1 are dispensable for growth on methanol. J. Bacteriol. 186, 22-28. doi: 10.1128/JB.186.1.2228.2004

Claudel-Renard, C., Chevalet, C., Faraut, T., and Kahn, D. (2003). Enzyme-specific profiles for genome annotation: PRIAM. Nucleic Acids Res. 31, 6633-6639. doi: $10.1093 /$ nar/gkg847

Ditta, G., Stanfield, S., Corbin, D., and Helinski, D. R. (1980). Broad host range DNA cloning system for gram-negative bacteria: construction of a gene bank of Rhizobium meliloti. Proc. Natl. Acad. Sci. U.S.A. 77, 7347-7351. doi: 10.1073/pnas.77.12.7347

Dziewit, L., Adamczuk, M., Szuplewska, M., and Bartosik, D. (2011a). DIY series of genetic cassettes useful in construction of versatile vectors specific for Alphaproteobacteria. J. Microbiol. Methods 86, 166-174. doi: 10.1016/j.mimet.2011.04.016

Dziewit, L., Czarnecki, J., Wibberg, D., Radlinska, M., Mrozek, P., Szymczak, M., et al. (2014). Architecture and functions of a multipartite genome of the methylotrophic bacterium Paracoccus aminophilus JCM 7686, containing primary and secondary chromids. BMC Genomics 15:124. doi: 10.1186/14712164-15-124 
Dziewit, L., Dmowski, M., Baj, J., and Bartosik, D. (2010). Plasmid pAMI2 of Paracoccus aminophilus JCM 7686 carries N,N-dimethylformamide degradation-related genes whose expression is activated by a LuxR family regulator. Appl. Environ. Microbiol. 76, 1861-1869. doi: 10.1128/AEM. 01926-09

Dziewit, L., Jazurek, M., Drewniak, L., Baj, J., and Bartosik, D. (2007). The SXT conjugative element and linear prophage N15 encode toxinantitoxin-stabilizing systems homologous to the tad-ata module of the Paracoccus aminophilus plasmid pAMI2. J. Bacteriol. 189, 1983-1997. doi: 10.1128/JB.01610-06

Dziewit, L., Kuczkowska, K., Adamczuk, M., Radlinska, M., and Bartosik, D. (2011b). Functional characterization of the type II PamI restrictionmodification system derived from plasmid pAMI7 of Paracoccus aminophilus JCM 7686. FEMS Microbiol. Lett. 324, 56-63. doi: 10.1111/j.1574-6968.2011.02388.x

Funke, G., Frodl, R., and Sommer, H. (2004). First comprehensively documented case of Paracoccus yeei infection in a human. J. Clin. Microbiol. 42, 3366-3368. doi: 10.1128/JCM.42.7.3366-3368.2004

Gibson, T. J. (1984). Studies on Epstein-Barr Genome. Ph.D. thesis, University of Cambridge.

Heinl, S., Wibberg, D., Eikmeyer, F., Szczepanowski, R., Blom, J., Linke, B., et al. (2012). Insights into the completely annotated genome of Lactobacillus buchneri CD034, a strain isolated from stable grass silage. J. Biotechnol. 161, 153-166. doi: 10.1016/j.jbiotec.2012.03.007

Karp, P. D., Paley, S. M., Krummenacker, M., Latendresse, M., Dale, J. M., Lee, T. J., et al. (2010). Pathway Tools version 13.0: integrated software for pathway/genome informatics and systems biology. Brief. Bioinform. 11, 40-79. doi: 10.1093/bib/bbp043

Kelly, D. P., Rainey, F. A., and Wood, A. P. (2006). “The genus Paracoccus," in Prokaryotes, eds M. Dworkin, S. Falkow, E. Rosenberg, K.-H. Schleifer and E. Stackebrandt (New York, NY: Springer), 232-249.

Keltjens, J. T., Pol, A., Reimann, J., and Op den Camp, H. J. (2014). PQQdependent methanol dehydrogenases: rare-earth elements make a difference. Appl. Microbiol. Biotechnol. 98, 6163-6183. doi: 10.1007/s00253-014-5766-8

Kim, S. G., Bae, H. S., and Lee, S. T. (2001). A novel denitrifying bacterial isolate that degrades trimethylamine both aerobically and anaerobically via two different pathways. Arch. Microbiol. 176, 271-277. doi: 10.1007/s002030 100319

Kim, S. G., Bae, H. S., Oh, H. M., and Lee, S. T. (2003). Isolation and characterization of novel halotolerant and/or halophilic denitrifying bacteria with versatile metabolic pathways for the degradation of trimethylamine. FEMS Microbiol. Lett. 225, 263-269. doi: 10.1016/S0378-1097(03)00530-5

Kovach, M. E., Phillips, R. W., Elzer, P. H., Roop, R. M. II., and Peterson, K. M. (1994). pBBR1MCS: a broad-host-range cloning vector. BioTechniques 16, 800-802.

Kushner, S. R. (1978). “An improved method for transformation of E. coli with ColE1 derived plasmids," in Genetic Engineering, eds H. B. Boyer and S. Nicosia (Amsterdam: Elsevier/North-Holland), 17-23.

Lee, J. H., Kim, Y. S., Choi, T. J., Lee, W. J., and Kim, Y. T. (2004). Paracoccus haeundaensis sp. nov., a Gram-negative, halophilic, astaxanthin-producing bacterium. Int. J. Syst. Evol. Microbiol. 54, 1699-1702. doi: 10.1099/ijs.0.63146-0

Li, K., Wang, S., Shi, Y., Qu, J., Zhai, Y., Xu, L., et al. (2011). Genome sequence of Paracoccus sp. Strain TRP, a chlorpyrifos biodegrader. J. Bacteriol. 193, 1786-1787. doi: 10.1128/JB.00014-11

Lidbury, I., Murrell, J. C., and Chen, Y. (2014). Trimethylamine N-oxide metabolism by abundant marine heterotrophic bacteria. Proc. Natl. Acad. Sci. U.S.A. 111, 2710-2715. doi: 10.1073/pnas.1317834111

Lipski, A., Reichert, K., Reuter, B., Sproer, C., and Altendorf, K. (1998). Identification of bacterial isolates from biofilters as Paracoccus alkenifer sp. nov. and Paracoccus solventivorans with emended description of Paracoccus solventivorans. Int. J. Syst. Bacteriol. 48, 529-536. doi: 10.1099/00207713-482-529

Liu, X. Y., Wang, B. J., Jiang, C. Y., and Liu, S. J. (2006). Paracoccus sulfuroxidans sp. nov., a sulfur oxidizer from activated sludge. Int. J. Syst. Evol. Microbiol. 56, 2693-2695. doi: 10.1099/ijs.0.64548-0

Liu, Y., Gan, L., Chen, Z., Megharaj, M., and Naidu, R. (2012). Removal of nitrate using Paracoccus sp. YF1 immobilized on bamboo carbon. J. Hazard. Mater. 229-230, 419-425. doi: 10.1016/j.jhazmat.2012.06.029
Meyer, F., Goesmann, A., McHardy, A. C., Bartels, D., Bekel, T., Clausen, J., et al. (2003). GenDB - an open source genome annotation system for prokaryote genomes. Nucleic Acids Res. 31, 2187-2195. doi: 10.1093/nar/ gkg312

Nayak, D. D., and Marx, C. J. (2014). Methylamine utilization via the $N$ methylglutamate pathway in Methylobacterium extorquens PA1 involves a novel flow of carbon through $\mathrm{C} 1$ assimilation and dissimilation pathways. J. Bacteriol. 196, 4130-4139. doi: 10.1128/JB.02026-14

Newton, R. J., Griffin, L. E., Bowles, K. M., Meile, C., Gifford, S., Givens, C. E., et al. (2010). Genome characteristics of a generalist marine bacterial lineage. ISME J. 4, 784-798. doi: 10.1038/ismej.2009.150

Petersen, J., Brinkmann, H., Bunk, B., Michael, V., Päuker, O., and Pradella, S. (2012). Think pink: photosynthesis, plasmids and the Roseobacter clade. Environ. Microbiol. 14, 2661-2672. doi: 10.1111/j.1462-2920.2012.02806.x

Petersen, J., Frank, O., Göker, M., and Pradella, S. (2013). Extrachromosomal, extraordinary and essential-the plasmids of the Roseobacter clade. Appl. Microbiol. Biotechnol. 97, 2805-2815. doi: 10.1007/s00253-013-4746-8

Philippe, N., Alcaraz, J. P., Coursange, E., Geiselmann, J., and Schneider, D. (2004). Improvement of pCVD442, a suicide plasmid for gene allele exchange in bacteria. Plasmid 51, 246-255. doi: 10.1016/j.plasmid.2004. 02.003

Ras, J., Van Ophem, P. W., Reijnders, W. N., Van Spanning, R. J., Duine, J. A., Stouthamer, A. H., et al. (1995). Isolation, sequencing, and mutagenesis of the gene encoding NAD- and glutathione-dependent formaldehyde dehydrogenase (GD-FALDH) from Paracoccus denitrificans, in which GD-FALDH is essential for methylotrophic growth. J. Bacteriol. 177, 247-251.

Reece, K. S., and Phillips, G. J. (1995). New plasmids carrying antibiotic-resistance cassettes. Gene 165, 141-142. doi: 10.1016/0378-1119(95)00529-F

Sambrook, J., and Russell, D. W. (2001). Molecular Cloning: A Laboratory Manual. New York, NY: Cold Spring Harbor Laboratory Press.

Sanjeevkumar, S., Nayak, A. S., Santoshkumar, M., Siddavattam, D. and Karegoudar, T. B. (2013). Paracoccus denitrificans SD1 mediated augmentation with indigenous mixed cultures for enhanced removal of N,N-dimethylformamide from industrial effluents. Biochem. Eng. J. 79, 1-6. doi: 10.1016/j.bej.2013.06.016

Siller, H., Rainey, F. A., Stackebrandt, E., and Winter, J. (1996). Isolation and characterization of a new gram-negative, acetone-degrading, nitrate-reducing bacterium from soil, Paracoccus solventivorans sp. nov. Int. J. Syst. Bacteriol. 46, 1125-1130. doi: 10.1099/00207713-46-4-1125

Simon, R., Priefer, U., and Pühler, A. (1983). A broad host range mobilization system for in vivo genetic-engineering - transposon mutagenesis in gramnegative bacteria. Bio-Technology 1, 784-791. doi: 10.1038/nbt1183-784

Sun, M., Luo, Y., Teng, Y., Christie, P., Jia, Z., and Li, Z. (2013). Tenax TA extraction to understand the rate-limiting factors in methyl-beta-cyclodextrinenhanced bioremediation of PAH-contaminated soil. Biodegradation 24, 365-375. doi: 10.1007/s10532-012-9593-2

Trotsenko, Y. A., and Murrell, J. C. (2008). Metabolic aspects of aerobic obligate methanotrophy. Adv. Appl. Microbiol. 63, 183-229. doi: 10.1016/S00652164(07)00005-6

Tsubokura, A., Yoneda, H., and Mizuta, H. (1999). Paracoccus carotinifaciens sp. nov., a new aerobic gram-negative astaxanthin-producing bacterium. Int. J. Syst. Bacteriol. 49(Pt 1), 277-282. doi: 10.1099/00207713-49-1-277

Turova, T. P., Kuznetsov, B. B., Doronina, N. V., and Trotsenko Iu, A. (2001). Phylogenetic analysis of aerobic methylotrophic bacteria, using dichloromethane. Mikrobiologiia 70, 92-97. doi: 10.1023/A:1004801106488

Urakami, T., Araki, H., Oyanagi, H., Suzuki, K., and Komagata, K. (1990). Paracoccus aminophilus sp. nov. and Paracoccus aminovorans sp. nov., which utilize N,N-dimethylformamide. Int. J. Syst. Bacteriol. 40, 287-291. doi: 10.1099/00207713-40-3-287

van Der Palen, C. J., Slotboom, D. J., Jongejan, L., Reijnders, W. N., Harms, N., Duine, J. A., et al. (1995). Mutational analysis of mau genes involved in methylamine metabolism in Paracoccus denitrificans. Eur. J. Biochem. 230, 860-871. doi: 10.1111/j.1432-1033.1995.tb20629.x

Van Spanning, R. J., Wansell, C. W., De Boer, T., Hazelaar, M. J., Anazawa, H., Harms, N., et al. (1991). Isolation and characterization of the moxJ, moxG, moxI, and moxR genes of Paracoccus denitrificans: inactivation of moxJ, moxG, and moxR and the resultant effect on methylotrophic growth. J. Bacteriol. 173, 6948-6961. 
Wilson, S. M., Gleisten, M. P., and Donohue, T. J. (2008). Identification of proteins involved in formaldehyde metabolism by Rhodobacter sphaeroides. Microbiology 154, 296-305. doi: 10.1099/mic.0.2007/ 011346-0

Wood, A. P., and Kelly, D. P. (1977). Heterotrophic growth of Thiobacillus A2 on sugars and organic acids. Arch. Microbiol. 113, 257-264. doi: 10.1007/BF00492033

Zhu, Y., Jameson, E., Parslow, R. A., Lidbury, I., Fu, T., Dafforn, T. R., et al. (2014). Identification and characterization of trimethylamine $\mathrm{N}$-oxide (TMAO) demethylase and TMAO permease in Methylocella silvestris BL2. Environ. Microbiol. 16, 3318-3330. doi: 10.1111/1462-2920.12585
Conflict of Interest Statement: The authors declare that the research was conducted in the absence of any commercial or financial relationships that could be construed as a potential conflict of interest.

Copyright (๑) 2015 Dziewit, Czarnecki, Prochwicz, Wibberg, Schlüter, Pühler and Bartosik. This is an open-access article distributed under the terms of the Creative Commons Attribution License (CC BY). The use, distribution or reproduction in other forums is permitted, provided the original author(s) or licensor are credited and that the original publication in this journal is cited, in accordance with accepted academic practice. No use, distribution or reproduction is permitted which does not comply with these terms. 